of the additional proposals so as to improve postgraduate education training still further. Training in Australia and New Zealand where there has been a unified training grade for many years, and where the fellowship examination is at the very least equal to UK membership, only lasts five years; reducing the duration of training in this country to a comparable level should therefore be a realistic aim.

The report will be the subject of a consultation process over the remaining part of this year. Psychiatric trainees need to ensure that their views in the future of training are heard through both the Collegiate Trainees Committee of the Royal College of Psychiatrists and the JDC. Both organisations have important and complementary roles in medical education and it is to be hoped that the two organisations can work closely together to ensure the best deal for psychiatric trainees.

\section{References}

Calman, K. C. (1993) Hosptial Doctors: training for the future. The Report of the Working Group on Specialist Medical Training. London: HMSO.

KEHOE, R. F. (1992) Specialist training. British Medical Journal, 305, 1290.

KisLeY, S. R. \& MorRiss, R. (1992) Specialist training. British Medical Journal, 305, 1021.

The submission of the Junior Doctors Committee to the Chief Medical Officer's working party on specialist training, certification and manpower. London: British Medical Association, 1992.

\title{
Expectations of prospective senior registrars and those who appoint them
}

\author{
JON IZAGUIRRE, Registrar, Schrodells Unit, Watford General Hospital, Vicarage Road \\ Watford WD1 8HB; and Lester Sireling, Consultant Psychiatrist, Barnet General \\ Hospital, Wellhouse Lane, Barnet EN5 3DJ
}

Access to a senior registrar post is growing more difficult because of increasing competition. The College Court of Electors and Joint Committee for High Psychiatric Training have agreed only two criteria for appointment as SR in Psychiatry (possession of MRCPsych and at least three years of general professional training), but, despite heavy workloads, busy timetables, and the need to prepare for the membership examination, clinical skills and dedication to patients will not ensure career progress if they are not accompanied by other aspects of training, sometimes with insufficient facilities and supervision. Indeed, Lewis (1991), after reviewing a group of applications for SR posts, found that the only variable which predicted likelihood of being shortlisted was having published: "Trainers generally believe that evidence of completed research and publications say more about a trainee than a good reference ever can".

Crisp (1990) suggested that all registrars complete a small project as a requirement of completion of training.

What do registrars believe they should offer SR appointment committees? How does this correlate with the views of those who appoint senior registrars? We asked both groups.

\section{The study}

This study was designed to reach all career registrars currently working in all 31 hospitals and psychiatric units throughout the North West Thames Regional Health Authority and those professors, senior lecturers and consultants who are, through their university and College positions, often involved in the appointment of senior registrars in the same region. They were asked which factors they would consider essential to obtain a SR post. The questionnaire consisted of ten factors, which had to be answered by ticking one of three categories for each factor: Essential, Useful but Not Essential, and Not Relevant.

These factors were:

(1) having research in progress

(2) completed research

(3) publications

(4) working in a teaching-hospital rotation

(5) experience of three years in adult general psychiatry

(6) managerial skills

(7) ability to work in a multidisciplinary team

(8) wide range of outside interests 


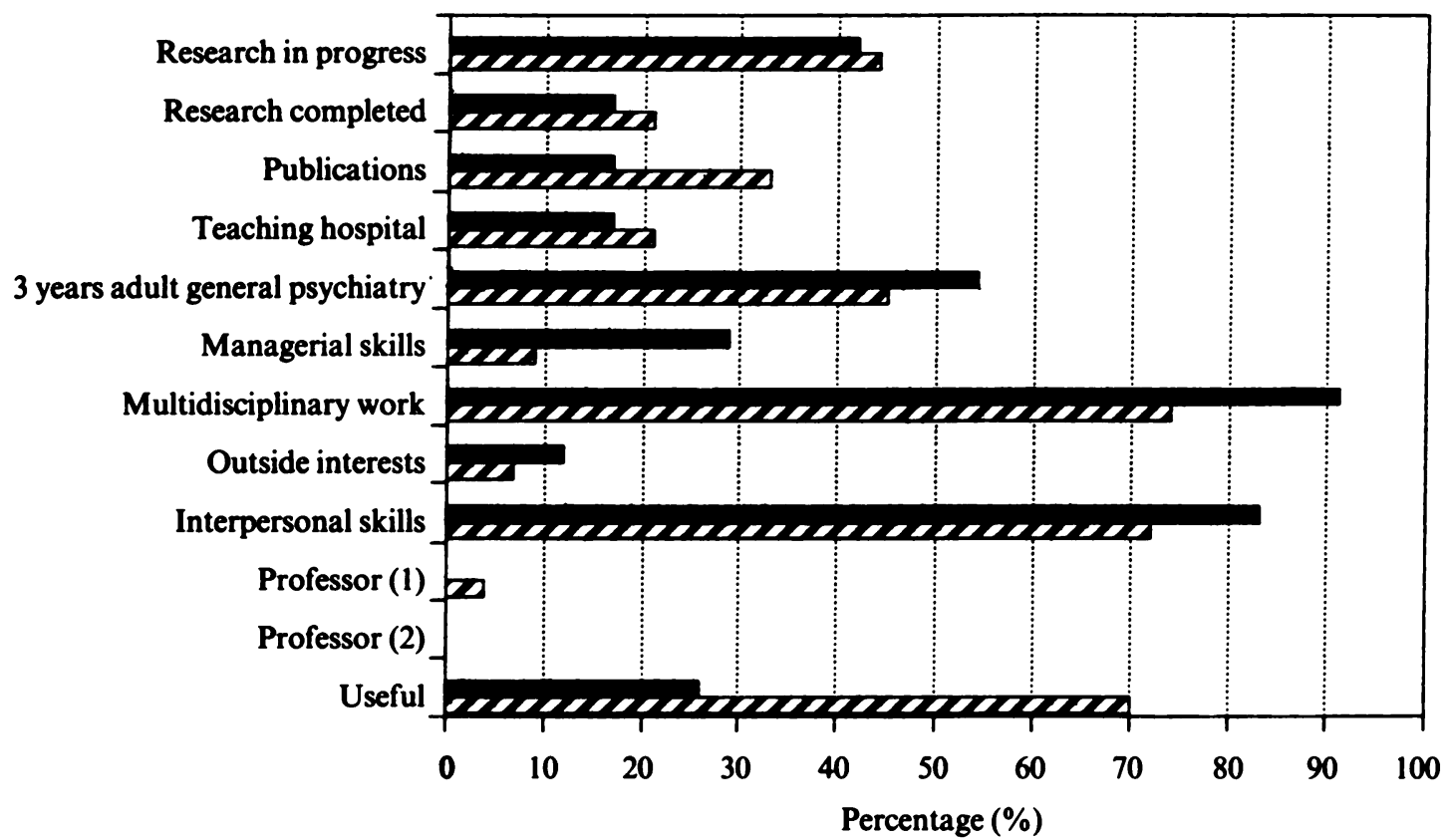

Figure 1. Factors considered essential to be appointed as SR ( $\square$ registrars, $\square$ consultants)

(9) good interpersonal skills

(10) Personal acquaintance with the professor in the scheme.

The possession of good clinical skills was not included since this is basic to medical practice. A space was reserved for those who wanted to add any other factor that they considered essential or useful. Those who did not respond were sent a reminder two months later. The data were analysed using $\chi^{2}$ method with Yates' correction and with a $5 \%$ significance level $(P<0.05)$.

\section{Findings}

Sixty-four registrars were sent the questionnaire of whom 43 replied (67.1\% response rate); 24 out of 29 consultants replied $(82.7 \%)$.

Almost all factors were ticked as being at least useful by a majority of respondents, with only one exception: consultants did not think that personal acquaintance with the professor was useful. Therefore, we concentrated on examining which factors were considered essential (see Fig. 1). Low priority was given to research by trainees and seniors alike: less than half of each group considered publications, research completed or even in progress as essential when applying for SR jobs. Twice as many juniors as seniors (33\% v. $17 \%)$ thought publications essential. Conversely, three times as many seniors thought managerial skills essential $(29 \%$ v. $9 \%)$. Threequarters or more of both groups agreed on the importance of good interpersonal skills and the ability to work in a multidisciplinary team.

Two (cynical or disillusioned?) registrars claimed that personal acquaintance with the professor in the scheme was essential for appointment, but the biggest difference between the groups was that $69 \%$ of trainees considered this useful, whereas only $26 \%$ of the seniors thought so, a statistically significant difference. It is interesting to note that two of them were professors. Not all the questionnaires contained additional proposed factors. Among those which did, the most commonly mentioned by the juniors was the importance of a convincing performance at the interview. Some seniors included the candidate's personal characteristics (e.g. stable, stimulating, reliable, etc.) as very important. Good clinical skills and professional ability (which had been deliberately omitted from the questionnaire) were mentioned by only six respondents.

\section{Comments}

The finding that a majority of registrars do not consider it essential to do any research contrasts with a similar study carried out in the Midlands (Junaid \& Staines, 1990) in which $76 \%$ of a heterogeneous group of trainees said it was. This result is surprising enough, but why did the consultants also give research a low priority, and why did the majority of them regard it as essential for the candidate to have good interpersonal skills? It seems unlikely that 
consultants were really looking for exceptional personal qualities when choosing a candidate, and it would be expected that they would concentrate on less arguable and more specific aspects of the curriculum. In fact, of the most recently appointed senior registrars in psychiatry for the North West Thames Regional Health Authority (Dr Angela Jones, personal communication) those who were appointed in adult psychiatry have had research published and all have completed some research projects. However, only two of the four SRs appointed to mental handicap rotations and only one out of three appointees to child and adolescent psychiatry had published research; this suggests that in certain disciplines the competition is less fierce. There is possibly a conflict for consultants between their original convictions and their practice when selecting candidates. If there is not much difference in the training of the candidates as specified in their curricula vitae, the selectors may scrutinise the research sections of the application forms in search of clues to the aid of short-listing. Consultants may be looking at factors other than research to appoint a candidate, but this will happen after the short-list process has made a selection according to research merits. Regardless of the reason, it is worrying to see that the registrars' response seems to show that they are not really aware of this.

The higher proportion of consultants considering it essential to have managerial skills might be because of the increasing pressure on them to undertake these responsibilities. At present, provisions for management training are restricted to SR level, although it can be speculated that more emphasis will be put on this aspect of registrar training. It is important that trainees discuss their medium-term and long-term career plans with their educational supervisor and clinical tutor early in their training.

Senior registrars should also be encouraged to discuss this matter with more junior colleagues as part of their supervision.

\section{Acknowlegements}

We wish to thank the Merck Research Committee for funding this study, Dr Angela Jones for providing us with valuable information and Dr Shôn Lewis for his comments.

\section{References}

CRISP, A. H. (1990) The case for teaching and research experience and education within basic specialist training (registrar grade) in psychiatry. Psychiatry Bulletin, 14, 163-164.

Junaid, O. \& Staines J. (1990) Career progression in psychiatry: Perceptions and realities. Psychiatric Bulletin. 14, 486-489.

LEWIS, S. (1991) The right stuff? A prospective controlled trial of trainees' research. Psychiatric Bulletin, 15,478-480.

The Royal College of Psychiatrists (1987) Handbook for Inceptors and Trainees in Psychiatry, 86-87.

\section{The 1994 Senior Registrars Residential Conference}

The 1994 Senior Registrars Residential Conference will take place at the University of York on 14 to 16 April.

Workshops will include presentation skills, media training, theory and management of aggressive patients, witness skills, research methodology, medical ethics, first day as a consultant, NHS Reforms and writing scientific papers. Further information from Jean Wales at the College. 